\title{
Faktor-Faktor Yang Mempengaruhi Nilai Perusahaan Consumer Goods Yang Terdaftar Di BEI
}

\author{
Sheilla dan Khairina Natsir \\ Program Studi Manajemen Fakultas Ekonomi, Universitas Tarumanagara, Jakarta \\ Email: sheillanirwan@gmail.com
}

\begin{abstract}
The purpose of this study was to determine the effect of profitability, dividend policy, and leverage on the value of the firm of the consumer goods sectors listed on Indonesia Stock Exchance in the period 2013-2017. The proxy used to measure firm value is $P B V$ ratio, profitability is measured by ROE ratio, dividend policy measured by DPR ratio, and leverage measured by DER ratio. The research method used is causal research method and uses quantitative data and purposive sampling method. This study uses secondary data obtained from the annual report of consumer goods companies through the official website of Indonesia Stock Exchange www.idx.co.id and the official websites of the company under study. This study uses a sample of 17 companies with multiple regression model and data processing is done through the Eviews 9.0 software program, The results of the study shows that partially profitability and leverage have a significant effect on firm value, while dividend policy has no significant effect on firm value.
\end{abstract}

Keywords: profitability, dividend policy, leverage, Value of the Firm.

Abstrak: Tujuan dari penelitian ini adalah untuk mengetahui pengaruh profitabilitas, kebijakan dividen, dan leverage terhadap nilai perusahaan sektor consumer goods yang terdaftar di Bursa Efek Indonesia pada periode 2013-2017. Proksi yang digunakan untuk mengukur variabel nilai perusahaan adalah PBV, profitabilitas diukur dengan ROE, kebijakan dividen diukur dengan DPR, dan leverage diukur dengan DER. Metode penelitian yang digunakan adalah metode penelitian kausal dan menggunakan data kuantitatif serta metode purposive sampling. Penelitian ini menggunakan data sekunder yang diperoleh dari laporan tahunan perusahaan consumer goods melalui website resmi Bursa Efek Indonesia www.idx.co.id dan website resmi perusahaan yang diteliti. Penelitian ini menggunakan sampel sebanyak 17 perusahaan dengan model regresi berganda dan pengolahan data dilakukan melalui program software Eviews 9.0. Hasil penelitian menunjukan secara parsial profitabilitas dan leverage berpengaruh secara signifikan terhadap nilai perusahaan, sedangkan kebijakan dividen berpengaruh tidak signifikan terhadap nilai perusahaan.

Kata kunci: Profitabilitas, Kebijakan Dividen, Leverage, Nilai Perusahaan.

\section{LATAR BELAKANG}

Persaingan bisnis yang terjadi membuat setiap perusahaan berkompetisi meningkatkan kinerja agar mencapai tujuannya. Untuk mencapai tujuannya, perusahaan berlomba agar dapat menarik perhatian investor. Perusahaan tidak hanya sekedar mencari laba sebesar-besarnya, tetapi juga meningkatkan kemakmuran pemilik atau pemegang saham. Tujuan utama yang harus dicapai perusahaan adalah memaksimumkan 
kemakmuran pemilik saham melalui maksimisasi nilai perusahaan (Sartono, 2001:4). Nilai perusahaan merupakan harga yang bersedia dibayar oleh calon pembeli apabila perusahaan tersebut dijual dan nilai perusahaan dinilai berdasarkan harga saham (Husnan \& Pujiastuti, 2012:6). Nilai perusahaan merupakan indikator penting yang menentukan akses sumber dana perusahaan karena berimbas kepada keputusan investasi para investor. Hal ini dikarenakan nilai perusahaan mencerminkan keadaan perusahaan tersebut. Menurut (Harmono, 2009:1) Nilai perusahaan yang tinggi mengindikasikan kekayaan para pemegang saham juga tinggi. Naik turunnya nilai perusahaan dapat dipengaruhi oleh faktor eksternal dan internal. Faktor internal merupakan faktor yang paling diperhatikan. Hal ini dikarenakan faktor ini merupakan faktor yang dapat dikendalikan oleh perusahaan. Faktorfaktor internal yang dapat mempengaruhi nilai perusahaan dibagi menjadi faktor kebijakan dan faktor kinerja. Faktor kebijakan yang mempengaruhi nilai perusahaan berupa kebijakan dividen, kebijakan hutang, keputusan pendanaan, keputusan investasi dan leverage. Dalam faktor kinerja dapat berupa profitabilitas dan likuiditas. Selain faktor kebijakan dan kinerja, ukuran perusahaan juga menjadi faktor yang mempengaruhi nilai perusahaan.

Profitabilitas merupakan faktor penting dalam keberlangsungan perusahaan kedepannya. Profitabilitas perusahaan dapat mempengaruhi kebijakan investor sebagai acuan mereka untuk melakukan investasi. Menurut (Sartono, 2001:122) "Profitabilitas adalah kemampuan perusahaan untuk memperoleh laba dalam hubungannya dengan penjualan, total aktiva maupun modal sendiri." Laba bersih yang didapat oleh perusahaan dalam pengoperasiannya merupakan keuntungan perusahaan yang dapat dibagikan kepada para pemilik atau pemegang saham. Maka semakin besar laba bersih sebuah perusahaan, semakin besar juga kemampuan perusahaan untuk membayar dividennya.

Kebijakan dividen pada dasarnya adalah penentuan pembagian porsi laba yang akan dibagikan kepada para pemilik atau pemegang saham. Melalui kebijakan dividen perusahaan menentukan keputusan untuk membayarkan arus kas kepada investor atau akan ditahan dalam bentuk laba ditahan untuk keperluan investasi perusahaan dalam rangka memperbesar usahanya. Besarnya dividen yang dibagikan perusahaan kepada investor berbeda-beda tergantung pada kebijakan dividen masing-masing perusahaan. Jika besarnya dividen yang dibagikan meningkat, maka akan berdampak pada peningkatan harga saham yang juga akan berakibat pada peningkatan nilai perusahaan. Dengan demikian, kebijakan dividen merupakan salah satu keputusan yang paling penting (Mahalang'ang'a Murekefu \& Ouma, 2012).

Faktor penting lain yang juga mempengaruhi nilai perusahaan adalah leverage yang dihasilkan perusahaan. Leverage dapat dikatakan bahwa suatu rasio keuangan yang mengukur seberapa banyak perusahaan dibiayai dengan menggunakan hutang (Wiagustini, 2010:76) Suatu perusahaan dapat menggunakan hutang (leverage) sebagai sumber pendanaan perusahaan agar menghasilkan keuntungan lebih. Tetapi penggunaan hutang yang terlalu banyak akan mengakibatkan penurunan laba. Leverage menjadi prediksi risiko yang melekat pada suatu perusahaan. Artinya, nilai leverage yang semakin tinggi akan menggambarkan investasi yang dilakukan beresiko besar, sedangkan leverage yang kecil akan menunjukan investasi yang dilakukan beresiko kecil (Analisa, 2011). 


\section{KAJIAN TEORI}

\section{Teori Keagenan}

Teori keagenan adalah teori yang mengkaji hubungan, keterkaitan dan konflik antara pemilik dan manajemen usaha. Menurut Ni Putu \& Suartana (2014) perbedaan kepentingan pemilik saham dan manajemen akan membuat pemilik saham mengeluarkan biaya untuk mengawasi manajemen sehingga termotivasi untuk meningkatkan kinerjanya dalam menyejahterakan pemilik saham sehingga mempengaruhi nilai perusahaan.

Teori Sinyal

\section{Teori signalling}

merupakan sebuah tindakan yang diambil oleh manajemen perusahaan yang memberikan gambaran atau petunjuk kepada investor tentang bagaimana manajemen memandang prospek perusahaan (Besley \& Eugene F. Brigham, 2008:444).

\section{Trade-off Theory}

Trade off Theory mengacu pada penentuan dalam penggunaan utang atau modal di dalam struktur modal untuk menyetarakan biaya dan manfaat. Untuk menentukan struktur modal yang optimal ditentukan dengan menyeimbangkan manfaat dari pendanaan dengan utang (Brigham \& Houston, 2001).

\section{Nilai perusahaan}

Nilai perusahaan merupakan hal yang penting bagi investor karena merupakan indikator untuk menilai perusahaan secara keseluruhan (Nurlela \& Islahuddin, 2008) yang sering dikaitkan dengan harga saham (Siahaan, 2013). Peningkatan harga saham perusahaan juga akan meningkatkan nilai perusahaan (Liang, Huang \& Lin, 2011). Menurut Keown (2004) nilai perusahaan merupakan nilai pasar atas surat berharga hutang dan ekuitas perusahaan yang beredar.

\section{Profitabilitas}

Profitabilitas adalah kemampuan perusahaan memperoleh laba dalam hubungannya dengan penjualan, total aktiva maupun modal sendiri (Sartono, 2001:122). Serupa dengan pemikiran Sartono, Hanafi \& Halim (2000) menyebutkan bahwa profitabilitas mengukur kemampuan perusahaan untuk menghasilkan keuntungan pada tingkat penjualan, asset dan modal saham tertentu.

\section{Kebijakan Dividen}

Kebijakan dividen adalah keputusan apakah laba yang diperoleh perusahaan akan dibagikan kepada pemegang saham sebagai dividen atau akan ditahan dalam bentuk laba ditahan guna pembiayaan investasi di masa yang akan datang (Tampubolon, 2004). Teori mengenai kebijakan dividen menurut Brigham \& Houston (2001), antara lain:

\section{Dividend Irrelevance Theory}

Modigliani \& Miller (1963) menyatakan bahwa nilai perusahaan tidak dipengaruhi oleh kebijakan dividen dan hanya dipengaruhi oleh kemampuan dasar perusahaan dalam menghasilkan laba dan risiko bisnis. 


\section{Bird in The Hand}

Lintner (1962) menyatakan bahwa dibandingkan capital gain, investor lebih menyukai dividen untuk menghindari risiko. Rasio pembayaran dividen yang tinggi akan memaksimisasi nilai perusahaan karena investor lebih menyukai return dalam bentuk dividen saat ini dibandingkan dengan capital gain di masa yang akan datang meskipun capital gain memberikan return yang lebih tinggi.

\section{Tax preference Theory}

Teori tax preference merupakan teori yang menyatakan bahwa adanya pajak terhadap keuntungan dividen dan capital gain, mengakibatkan para investor lebih menyukai capital gain sebab dapat menunda pembayaran pajak (Ridla, 2005).

\section{Leverage}

Leverage merupakan rasio yang digunakan untuk mengukur sejauh mana aktiva perusahaan dibiayai dengan utang (Kasmir, 2014), artinya berapa besar beban utang yang ditanggung perusahaan dibandingkan dengan aktivanya.

Kerangka pemikiran yang digunakan dalam penelitian ini dapat dilihat pada gambar berikut:

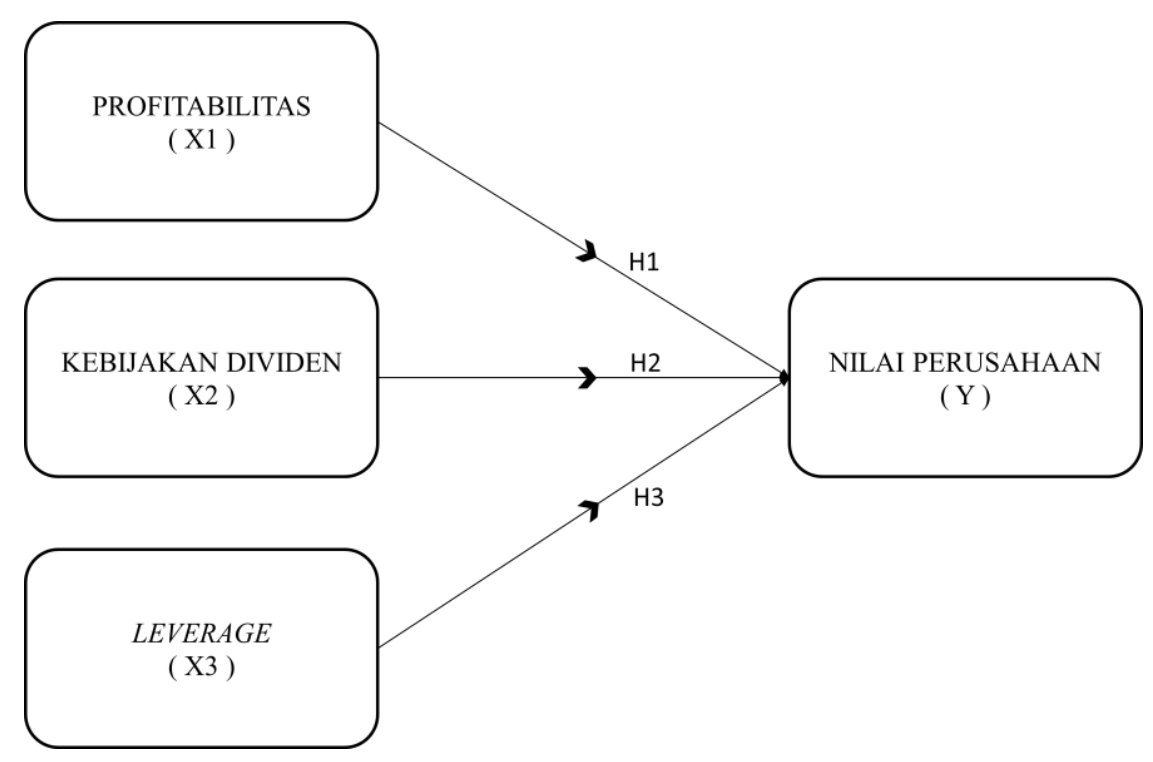

Gambar 1. Kerangka Penelitian

Dengan hipotesis sebagai berikut:

Berdasarkan kerangka teori dan pemikiran di atas, maka berikut hipotesis dalam penelitian ini:

$\mathrm{H}_{1}$ : Profitabilitas berpengaruh signifikan terhadap nilai perusahaan

$\mathrm{H}_{2}$ : Kebijakan dividen berpengaruh signifikan terhadap nilai perusahaan

$\mathrm{H}_{3}$ : Leverage berpengaruh signifikan terhadap nilai perusahaan 


\section{METODOLOGI}

Subjek yang digunakan dalam penelitian ini adalah perusahaan pada sektor consumer goods yang terdaftar di Bursa Efek Indonesia (BEI) pada tahun 2013-2017. Metode pemilihan sampel yang digunakan dalam penelitian ini adalah metode purposive sampling atau pemilihan sampel perusahaan yang telah berdasarkan kriteria tertentu sesuai dengan tujuan atau masalah penelitian dalam sebuah populasi.

Kriteria yang digunakan dalam penelitian adalah sebagai berikut: 1. Perusahaan consumer goods yang terdaftar di Bursa Efek Indonesia pada tahun 2013-2017; 2. Perusahaan consumer goods yang tidak melakukan IPO pada periode 2013-2017; 3. Perusahaan yang telah mempublikasikan laporan keuangannya yang berakhir setiap 31 Desember selama periode penelitian; 4. Perusahaan yang mempunyai data lengkap selama periode penelitian untuk faktor-faktor yang diteliti, yaitu profitabilitas, kebijakan dividen, leverage, dan nilai perusahaan; 5. Perusahaan consumer goods yang tidak mengalami kerugian selama tahun 2013-2017; 6. Perusahaan yang tidak mengalami delisting dan relisting selama tahun 2013-2017; 7. Perusahaan yang membagikan cash dividend secara berturut-turut pada tahun 2013-2017.

Objek penelitian ini adalah variabel yang digunakan yang terdiri dari satu variabel dependen dan tiga variabel independen. Variabel dependen yang digunakan dalam penelitian ini adalah nilai perusahaan, sedangkan variabel independen yang digunakan dalam penelitian ini adalah profitabilitas, kebijakan dividen, dan leverage.

Menurut Manoppo \& Arie (2016) nilai perusahaan dapat diukur dengan menggunakan rasio price to book value (PBV):

$$
\begin{aligned}
\text { PBV }(\text { Price to Book Value }) & =\frac{\text { Market Price per Share }}{\text { Book Value per Share }} \\
\text { Book Value per Share } & =\frac{\text { Total Equity }}{\text { Outstanding Share }}
\end{aligned}
$$

Profitabilitas mengukur kemampuan perusahaan menghasilkan keuntungan pada tingkat penjualan, aset, dan modal saham tertentu. Menurut Manoppo \& Arie (2016) profitabilitas dapat diukur dengan menggunakan rasio return on equity (ROE):

$$
\text { ROE }\left(\text { Return on Equity) }=\frac{\text { Net Income }}{\text { Total Equity }}\right.
$$

Kebijakan dividen merupakan keputusan apakah perusahaan akan membagikan laba kepada pemegang saham sebagai dividen atau ditahan dalam bentuk laba ditahan. Dalam penelitian Putra \& Lestari (2016) kebijakan dividen dapat diukur dengan menggunakan rasio dividend payout ratio (DPR):

$$
\text { DPR (Dividend Payout Ratio })=\frac{\text { Dividend }}{\text { Net Income }}
$$

Leverage merupakan pengukur berapa besar beban hutang yang ditanggung perusahaan untuk membiayai aktivanya. Dalam penelitian Sukrini (2012) leverage diukur dengan menggunakan rasio debt equity ratio (DER): 


$$
\text { DER }(\text { Debt Equity Ratio })=\frac{\text { Total Debt }}{\text { Total Equity }}
$$

\section{Hasil Uji}

Statistik deskriptif menurut Ghozali (2012:19) mengambarkan atau mendeskripsikan suatu data dilihat dari nilai rata-rata (mean), standar deviasi, varian, maksimum, minimum dari variabel yang diuji. Pada variabel dependen nilai perusahaan (PBV) nilai rata-rata (mean) sebesar 9,433824. Nilai tengah (median) terletak pada perusahaan Mayora Indah Tbk (MYOR) pada periode tahun 2014 sebesar 4,584672. Nilai maksimum untuk variabel nilai perusahaan (PBV) terletak pada perusahaan Unilever Indonesia Tbk (UNVR) pada periode tahun 2017 sebesar 82,44443. Sedangkan nilai minimum terletak pada perusahaan Wismilak Inti Makmur Tbk (WIIM) pada periode tahun 2017 sebesar 0,622604. Selain itu, standar deviasi adalah sebesar 15,09011.

Pada variabel independen profitabilitas (ROE), nilai rata-rata (mean) sebesar 0,313191. Nilai tengah (median) terletak pada perusahaan Indofood CBP Sukses Makmur Tbk (ICBP) pada periode tahun 2017 sebesar 0,174332 dan nilai maksimum terletak pada perusahaan Multi Bintang Indonesia Tbk (MLBI) pada periode tahun 2014 sebesar 1,435333 serta nilai minimum terletak pada perusahaan Wismilak Inti Makmur Tbk (WIIM) pada periode tahun 2017 sebesar 0,041499. Sedangkan, untuk standar deviasi adalah sebesar 0,357964 .

Pada variabel independen kebijakan dividen (DPR), nilai rata-rata (mean) sebesar 0,500740. Nilai tengah (median) terletak pada perusahaan Kalbe Farma Tbk (KLBF) pada periode tahun 2015 sebesar 0,432828 dan nilai maksimum terletak pada perusahaan Merck Tbk (MERK) pada periode tahun 2015 sebesar 1,540000 serta nilai minimum terletak pada perusahaan Wismilak Inti Makmur Tbk (WIIM) pada periode tahun 2013 sebesar 0,057130. Sedangkan, untuk standar deviasi adalah sebesar 0,315808.

Pada variabel independen leverage (DER), nilai rata-rata (mean) sebesar 0,797694. Nilai tengah (median) terletak pada perusahaan Gudang Garam Tbk (GGRM) pada periode tahun 2016 sebesar 0,591125 dan nilai maksimum terletak pada perusahaan Multi Bintang Indonesia Tbk (MLBI) pada periode tahun 2014 sebesar 3,028644 serta nilai minimum terletak pada perusahaan Delta Djakarta Tbk (DLTA) pada periode tahun 2017 sebesar 0,171405. Sedangkan, untuk standar deviasi adalah sebesar 0,617784.

Uji chow dilakukan untuk penentuan dalam penggunaan model common effect atau fixed effect yang digunakan. Hasil pengujian menunjukan nilai probabilitas cross section $F$ sebesar 0,0000 yang berarti bahwa fixed effect model terpilih untuk digunakan dalam penelitian ini. Uji hausman dilakukan untuk menentukan model regresi terbaik antara fixed effect model dengan random effect model. Hasil dari uji hausman ini menunjukan nilai probabilitas cross section random sebesar 0,0022 yang berarti bahwa model terbaik untuk penelitian ini adalah fixed effect model.

Tabel 1. Hasil Pengolahan

\begin{tabular}{crrrr}
\hline \hline Variable & Coefficient & Std. Error & t-Statistic & Prob. \\
\hline \hline C & -0.488493 & 1.567366 & -0.311665 & 0.7563 \\
ROE & 12.38165 & 4.317301 & 2.867915 & 0.0056 \\
DPR & 0.682797 & 1.996338 & 0.342025 & 0.7334 \\
DER & 7.148852 & 1.620709 & 4.410942 & 0.0000
\end{tabular}


Effects Specification

Cross-section fixed (dummy variables)

\begin{tabular}{lrll} 
R-squared & 0.965131 & Mean dependent var & 9.433824 \\
Adjusted R-squared & 0.954939 & S.D. dependent var & 15.09011 \\
S.E. of regression & 3.203264 & Akaike info criterion & 5.368542 \\
Sum squared resid & 666.9587 & Schwarz criterion & 5.943284 \\
Log likelihood & -208.1630 & Hannan-Quinn criter. & 5.599719 \\
F-statistic & 94.69164 & Durbin-Watson stat & 1.081966 \\
Prob(F-statistic) & 0.000000 & & \\
\hline
\end{tabular}

Berdasarkan hasil pengolahan data yang dilakukan, maka diperoleh susunan persamaan regresi linear berganda sebagai berikut:

$$
P B V_{i, t}=-0.488493+12.38165 R_{0} E_{i, t}+0.682797 D P R_{i, t}+\operatorname{l.148852DER~}_{i, t}+\varepsilon_{i, t}
$$

Berdasarkan tabel 1 diatas dapat diketahui hasil uji f yang menunjukan pengujian pengaruh variabel independen yang dimasukkan dalam model mempunyai pengaruh secara bersama-sama atau simultan terhadap variabel dependen. Uji $\mathrm{f}$ pada penelitian ini menggunakan tingkat probabilitas signifikansi sebesar 5\% $(\alpha=0,05)$. Probabilitas pada $F$ statistic adalah sebesar 0,0000 yang berarti nilai probabilitas ( $F$-statistic) lebih kecil daripada tingkat signifikasi 0,05 sehingga $\mathrm{H}_{0}$ ditolak. Hal tersebut dapat menunjukkan bahwa profitabilitas, kebijakan dividen, dan leverage secara simultan berpengaruh terhadap nilai perusahaan.

Berdasarkan tabel 1 diatas dapat diketahui hasil uji t yang menjelaskan pengaruh signifikan dari variabel independen terhadap variabel dependen pada penelitian secara parsial. Uji t pada penelitian ini menggunakan tingkat probabilitas signifikansi sebesar 5\% $(\alpha=0,05)$. Probabilitas pada variabel profitabilitas (ROE) memiliki nilai sebesar 0,0056 dengan nilai koefisien kearah positif sebesar 12,38165 terhadap nilai perusahaan oleh karena itu hipotesis pertama (H1) diterima. Probabilitas pada variabel kebijakan dividen (DPR) memiliki nilai sebesar 0,7334 dengan nilai koefisien kearah positif sebesar 0,682797 terhadap nilai perusahaan oleh karena itu hipotesis kedua (H2) ditolak. Probabilitas pada variabel leverage (DER) memiliki nilai sebesar 0,0000 dengan nilai koefisien kearah positif sebesar 7,148852 terhadap nilai perusahaan oleh karena itu hipotesis ketiga (H3) diterima.

\section{DISKUSI}

Hasil pengujian statistik dengan uji t menunjukan bahwa variabel profitabilitas dan kebijakan dividen berpengaruh signifikan positif terhadap nilai perusahaan. Hasil pengujian statistik dengan uji $\mathrm{t}$ menunjukan bahwa variabel kebijakan dividen tidak berpengaruh secara sigifikan terhadap nilai perusahaan.

\section{KESIMPULAN}

Berdasarkan hasil pengujian data dalam penelitian ini, maka dapat disimpulkan bahwa variabel profitabilitas dan leverage berpengaruh signifikan positif terhadap nilai 
perusahaan. Sedangkan hasil pengujian statistik dengan uji t menunjukkan bahwa variabel kebijakan dividen tidak berpengaruh signifikan terhadap nilai perusahaan. Keterbatasan dari penelitian ini adalah hanya mengacu pada tiga variabel independen dan berfokus pada perusahaan manufaktur di sektor consumer goods. Bagi perusahaan, peneliti menyarankan untuk mempertimbangkan utang sebagai alternatif dalam pendanaan perusahaan untuk meningkatkan nilai perusahaan. Bagi investor, peneliti menyarankan investor tidak perlu berfokus pada besaran dividen yang dibagikan oleh perusahaan tetapi dapat mempertimbangkan riwayat capital gain, profitabilitas dan leverage dari perusahaan. Bagi penelitian yang akan datang, peneliti menyarankan

\section{DAFTAR PUSTAKA}

Analisa, Y. (2011). Pengaruh Ukuran Perusahaan, Leverage, Profitabilitas dan Kebijakan Dividen Terhadap Nilai Perusahaan. Semarang: Universitas Diponegoro, (2), 1-28.

Besley, S., \& Eugene F. Brigham. (2008). Essentials of Managerial Finance (14th Edition). South-Western College Pub.

Brigham, E. F., \& Houston, J. F. (2001). Dasar-dasar Manajemen Keuangan. Buku satu, Edisi Kesepuluh. Jakarta: Salemba Empat.

Franco Modigliani, \& Miller, M. H. (1963). Corporate Income Taxes and the Cost of Capital: A Correction. The American Economic Review, Vol. 53, No. 3.

Ghozali, I. (2012). Aplikasi Analisis Multivariate Dengan Program IBM SPSS 20. Semarang: BPFE Universitas Diponegoro.

Hanafi, M. M., \& Halim, A. (2000). Analisis Laporan Keuangan. Yogyakarta: UPP AMP YKPN.

Harmono, D. (2009). Manajemen Keuangan Berbasis Balance Scorecard (Pendekatan). Jakarta: Bumi Aksara.

Husnan, S., \& Pujiastuti, E. (2012). Dasar-Dasar Manajemen Keuangan. Yogyakarta: UPP STIM YKPN.

Kasmir. (2014). Analisis Laporan Keuangan (Ed Revisi). Jakarta: Rajawali Pers.

Keown, A. J. (2004). Manajemen Keuangan: Prinsip-Prinsip dan Aplikasi (Edisi 9). Jakarta: Indeks.

Liang, C., Huang, T.T., \& Lin, W. (2011). Does Ownership Structure Affect Firm Value ? Intellectual Capital Across Industries Perspective. Journal of Intellectual Capital, 12(4).

Lintner, J. (1962). Dividend, Earning, Leverage, Stock Prices, and the Supply of Capital to Corporation. The Review of Economics and Statistics, Vol.44, No. 3: 243-269.

Mahalang'ang'a Murekefu, T., \& Ouma, O. P. (2012). The Relationship Between Dividend Payout and Firm Performance: a Study of Listed Companies in Kenya. European Scientific Journal May Edition, 8(9), 199-215.

Manoppo, H., \& Arie, F. V. (2016). Pengaruh Struktur Modal, Ukuran Perusahaan dan Profitabilitas Terhadap Nilai Perusahaan Otomotif yang Terdaftar di Bursa Efek Indonesia Periode 2011-2014. Jurnal EMBA, 4(2), 485-497.

Ni Putu, W., \& Suartana, I. W. (2014). Pengaruh Kepemilikan Manajerial Dan Kepemilikan Institusional Pada Nilai Perusahaan. E-Journal Akuntansi Universitas Udayana 9.3, 3, 575-590.

Nurlela, R., \& Islahuddin. (2008). Pengaruh Corporate Social Responsibility Terhadap Nilai Perusahaan Dengan Prosentase Kepemilikan Manajemen Sebagai Variabel 
Moderating (Studi Empiris Pada Perusahaan Yang Terdaftar Di Bursa Efek Jakarta). Jurnal Dan Prosiding SNA - Simposium Nasional Akuntansi, 11.

Putra, A. N. D. A., \& Lestari, P. V. (2016). Pengaruh Kebijakan Dividen, Likuiditas, Profitabilitas Dan Ukuran Perusahaan Terhadap Nilai Perusaan. E-JurnalManajemen Unud, 5(7), 4044-4070.

Ridla, R. (2005). Analisa Pengaruh Pengumuman Right Issue Terhadap Capital Gain dan Dividen Pada Perusahaan Non Manufaktur di Bursa Efek Jakarta. Jurnal Yogyakarta, Program Akuntansi Universitas Islam Indonesia.

Sartono, A. (2001a). Manajemen Keuangan. Yogyakarta: BPFE.

Sartono, A. (2001b). Manajemen Keuangan Teori dan Aplikasi (Edisi ke-4). Yogyakarta: BPFE.

Sartono, A. (2010). Manajemen Keuangan Teori dan Aplikasi (Edisi 4; BPFE, ed.). Yogyakarta.

Siahaan, F. O. P. (2013). The Effect of Good Corporate Governance Mechanism, Leverage, and Firm Size on Firm Value. GSTF Journal on Business Review (GBR) Vol.2 No.4,.

Sukrini, D. (2012). Kepemilikan Manajerial, Kepemilikan Institusional, Kebijakan Deviden dan Kebijakan Hutang Analisis Terhadap NIlai Perusahaan. Accounting Analysis Journal, 1(2).

Tampubolon, M. (2004). Manajemen Keuangan (Financial Management). Bogor: Ghalia Indonesia.

Wiagustini, N. L. P. (2010). Dasar-Dasar Manajemen Keuangan. Denpasar: Udayana University Press. 